\title{
Heteroepitaxy of Group IV-VI Nitrides by Atomic Layer Deposition
}

\author{
Jeffrey A. Klug, ${ }^{1, \text { a) }}$ Nicholas G. Becker, ${ }^{1,2}$ Nickolas R. Groll, ${ }^{1}$ Chaoyue Cao, ${ }^{1,2}$ Matthew S. Weimer, ${ }^{1,3}$ Michael \\ J. Pellin, ${ }^{1}$ John F. Zasadzinski, ${ }^{1,2}$ and Thomas Proslier ${ }^{1, b)}$ \\ 1) Materials Science Division, Argonne National Laboratory, Argonne, Illinois 60439, \\ USA \\ ${ }^{2)}$ Department of Physics, Illinois Institute of Technology, Chicago, Illinois 60616, \\ $U S A$ \\ ${ }^{3)}$ Department of Chemistry, Illinois Institute of Technology, Chicago, Illinois 60616, \\ $U S A$
}

Heteroepitaxial growth of selected group IV-VI nitrides on various orientations of sapphire $\left(\alpha\right.$ - $\left.\mathrm{Al}_{2} \mathrm{O}_{3}\right)$ is demonstrated using atomic layer deposition. High quality, epitaxial films are produced at significantly lower temperatures than required by conventional deposition methods. Characterization of electrical and superconducting properties of epitaxial films reveals a reduced room temperature resistivity and increased residual resistance ratio (RRR) for films deposited on sapphire compared to polycrystalline samples deposited concurrently on fused quartz substrates.

Transition metal nitrides exhibit a host of rich physics and functionality ranging from superconductivity to applications as refractory coatings 1 There is significant interest in epitaxial nitrides since epitaxy-induced changes in the crystallinity and morphology of thin films can influence both fundamental materials properties and device performance. Heteroepitaxial growth of $\mathrm{MoN}, \mathrm{NbN}$, and TiN has been explored by several methods, including reactive sputtering, $\stackrel{2}{4}^{4}$ pulsed laser deposition (PLD) chemical vapor deposition (CVD),$\underline{6}$ and polymer assisted deposition (PAD) ${ }^{7 / 8}$ Atomic layer deposition (ALD), which utilizes sequential self-limiting surface chemical reactions to deposit material in a layer-by-layer mode,, 910 offers several advantages over traditional growth techniques. ALD provides atomic-scale uniformity over large areas, unmatched conformality over complex-shaped substrates, and deposition temperatures well below those typically required by other methods.

While the ALD of metal nitrides is known to result in the formation of crystalline films in many cases, 11 little attention has been devoted to the investigation of heteroepitaxial growth on suitable single crystal substrates. Several groups have reported epitaxial ALD of AlN, ${ }^{12}$ GaN,, 13 , InN,, 14 and $\operatorname{In}_{x} \mathrm{Ga}_{1-x} \mathrm{~N}^{\sqrt{15}}$ films on sapphire $\left(\alpha-\mathrm{Al}_{2} \mathrm{O}_{3}\right)$ from organometallic precursors. Epitaxial GaN has also been reported on (111) GaAs using a chloride-ammonia process ${ }^{[16}$ However, apart from the group III nitrides, epitaxy of nitrides has been entirely unexplored in the ALD literature despite a large volume of studies concerning transition metal nitride ALD! 1117 In this letter we report the ALD of epitaxial MoN, $\mathrm{NbN}$, $\mathrm{Nb}_{x} \mathrm{Ti}_{1-x} \mathrm{~N}$, and TiN films on $c^{-}, m_{-}, a-$, and $r$-plane sapphire. Heteroepitaxial orientations were determined by x-ray diffraction (XRD) and the effects of substrate induced epitaxy on film resistivity and superconductivity are discussed. While several studies have examined superconductivity in ALD films, $\frac{18}{18}$ the effects of crys-

\footnotetext{
a) Electronic mail: jklug@anl.gov

b) Electronic mail: prolier@anl.gov
}

tallinity on film properties have thusfar not been reported.

ALD film growth was carried out in a custom-built hot-walled viscous flow reactor similar to that described elsewhere ${ }^{19}$ During ALD, a $360 \mathrm{sccm}$ flow of UHP $\mathrm{N}_{2}$ at 1.0 Torr served as purge and carrier gas. Prior to ALD, all substrates were cleaned via sonication in acetone, isopropanol, and deionized water. Nitride films were deposited at $450{ }^{\circ} \mathrm{C}$ using metal chlorides $\left(\mathrm{TiCl}_{4}\right.$, $\mathrm{NbCl}_{5}$, and $\left.\mathrm{MoCl}_{5}\right)$ and ammonia $\left(\mathrm{NH}_{3}\right)$ as precursors. $\mathrm{Nb}_{x} \mathrm{Ti}_{1-x} \mathrm{~N}$ samples were deposited using alternating TiN and NbN ALD cycles to achieve a desired composition. For these samples metallic $\mathrm{Zn}$ was used as an additional reactant for the reduction of the metal chlorides. ${ }^{20}$ X-ray diffraction (XRD) and x-ray reflectivity (XRR) were performed with a Philips X'Pert MRD diffractometer using $\mathrm{Cu} \mathrm{K} \alpha$ radiation $(\lambda=1.5418 \AA)$ and operated at $30 \mathrm{kV} / 30 \mathrm{~mA}$. Incident $\mathrm{x}$-ray beam conditioning was provided by a $60 \mathrm{~mm}$ graded parabolic W/Si mirror with a $0.8^{\circ}$ acceptance angle and a $1 / 32^{\circ}$ divergence slit. The reflected beam was collected with a sealed proportional detector positioned behind a $0.27^{\circ}$ parallel plate collimator and a pyrolytic graphite monochromator. Electrical resistivity down to $1.3 \mathrm{~K}$ was obtained via a four terminal measurement in a custom-built apparatus.

The epitaxial orientations determined by XRD for a series of MoN, NbN, TiN, and $\mathrm{Nb}_{0.8} \mathrm{Ti}_{0.2} \mathrm{~N}$ samples are summarized in Table I. For clarity, planes and directions for $\mathrm{MoN}$ and $\mathrm{Al}_{2} \mathrm{O}_{3}$ are described using the four-axis hexagonal reference basis. ${ }^{21}$ In all cases, films grown on sapphire were epitaxial while those grown concurrently on (001)Si and fused quartz (G.E. 124) substrates were polycrystalline. At least two twin variants were detected for all samples except the cases of MoN grown on $c$ - or $m$-plane $\mathrm{Al}_{2} \mathrm{O}_{3}$.

Specular and off-specular XRD scans of an $80 \mathrm{~nm}$ thick MoN film deposited on $c-\mathrm{Al}_{2} \mathrm{O}_{3}$ are shown in Fig. 11(a) and 1(b), respectively. A single $\delta$-MoN orientation was observed, $(0001)\langle 10 \overline{1} 0\rangle \mathrm{MoN} \|(0001)\langle 11 \overline{2} 0\rangle \mathrm{Al}_{2} \mathrm{O}_{3}$, which is consistent with the results reported for $\mathrm{MoN} / c-\mathrm{Al}_{2} \mathrm{O}_{3}$ prepared at $900^{\circ}$ by $\mathrm{PAD}{ }^{7}$ From analysis of the (0002) 
TABLE I. Orientational relationships between ALD nitride films and single crystal sapphire substrates determined by $\mathrm{x}$ ray diffraction.

\begin{tabular}{|c|c|c|}
\hline Film & Substrate & Epitaxial relationship \\
\hline $\mathrm{MoN}$ & $c-\mathrm{Al}_{2} \mathrm{O}_{3}$ & $(0001)\langle 10 \overline{1} 0\rangle \mathrm{MoN} \|(0001)\langle 11 \overline{2} 0\rangle \mathrm{Al}_{2} \mathrm{O}_{3}$ \\
\hline $\mathrm{NbN}$ & $c-\mathrm{Al}_{2} \mathrm{O}_{3}$ & $\begin{array}{l}(111)[1 \overline{1} 0] \mathrm{NbN} \|(0001)[10 \overline{1} 0] \mathrm{Al}_{2} \mathrm{O}_{3} \\
(111)[\overline{1} 10] \mathrm{NbN} \|(0001)[10 \overline{1} 0] \mathrm{Al}_{2} \mathrm{O}_{3}\end{array}$ \\
\hline $\mathrm{TiN}$ & $c-\mathrm{Al}_{2} \mathrm{O}_{3}$ & $\begin{array}{l}(111)[1 \overline{1} 0] \mathrm{TiN} \|(0001)[10 \overline{1} 0] \mathrm{Al}_{2} \mathrm{O}_{3} \\
(111)[\overline{1} 10] \mathrm{TiN} \|(0001)[10 \overline{1} 0] \mathrm{Al}_{2} \mathrm{O}_{3}\end{array}$ \\
\hline $\mathrm{MoN}$ & $m-\mathrm{Al}_{2} \mathrm{O}_{3}$ & $(11 \overline{2} 0)[1 \overline{1} 00] \mathrm{MoN} \|(10 \overline{1} 0)[1 \overline{2} 10] \mathrm{Al}_{2} \mathrm{O}_{3}$ \\
\hline $\mathrm{Nb}_{0.8} \mathrm{Ti}_{0.2} \mathrm{~N}$ & $a-\mathrm{Al}_{2} \mathrm{O}_{3}$ & $\begin{array}{l}(111)[1 \overline{1} 0] \mathrm{Nb}_{0.8} \mathrm{Ti}_{0.2} \mathrm{~N} \|(11 \overline{2} 0)[1 \overline{1} 00] \mathrm{Al}_{2} \mathrm{O}_{3} \\
(111)[\overline{1} 10] \mathrm{Nb}_{0.8} \mathrm{Ti}_{0.2} \mathrm{~N} \|(11 \overline{2} 0)[1 \overline{1} 00] \mathrm{Al}_{2} \mathrm{O}_{3} \\
(111)[1 \overline{1} 0] \mathrm{Nb}_{0.8} \mathrm{Ti}_{0.2} \mathrm{~N} \|(11 \overline{2} 0)[0001] \mathrm{Al}_{2} \mathrm{O}_{3} \\
(111)[\overline{1} 10] \mathrm{Nb}_{0.8} \mathrm{Ti}_{0.2} \mathrm{~N} \|(11 \overline{2} 0)[0001] \mathrm{Al}_{2} \mathrm{O}_{3}\end{array}$ \\
\hline $\mathrm{MoN}$ & $r-\mathrm{Al}_{2} \mathrm{O}_{3}$ & $\begin{array}{l}{[1 \overline{2} 12][10 \overline{1} 0] \mathrm{MoN} \|(1 \overline{1} 02)[\overline{1} 101] \mathrm{Al}_{2} \mathrm{O}_{3}} \\
{[1 \overline{2} 12][\overline{1} 010] \mathrm{MoN} \|(1 \overline{1} 02)[\overline{1} 101] \mathrm{Al}_{2} \mathrm{O}_{3}}\end{array}$ \\
\hline $\mathrm{TiN}$ & $r-\mathrm{Al}_{2} \mathrm{O}_{3}$ & $\begin{array}{l}(135)[1 \overline{2} 1] \mathrm{TiN} \|(1 \overline{1} 02)[\overline{1} 101] \mathrm{Al}_{2} \mathrm{O}_{3} \\
(\overline{1} \overline{3} \overline{5})[\overline{1} 2 \overline{1}] \mathrm{TiN} \|(1 \overline{1} 02)[\overline{1} 101] \mathrm{Al}_{2} \mathrm{O}_{3}\end{array}$ \\
\hline
\end{tabular}

and $\{20 \overline{2} 2\}$ film reflections, the out-of-plane (OP) mosaic and in-plane (IP) texture of the MoN film were $1.12 \pm 0.02^{\circ}$ and $1.8 \pm 0.03^{\circ}$, respectively (FWHM). A broad peak corresponding to the (111) reflection of cubic $\gamma-\mathrm{Mo}_{2} \mathrm{~N}$ was observed with approximately $1 / 120$ the integrated intensity of the $\mathrm{MoN}(0002)$ peak. This is consistent with a thin $\gamma-\mathrm{Mo}_{2} \mathrm{~N}$ layer at the film-substrate interface as observed in polycrystalline films deposited on AlN/quartz. ${ }^{[2]}$ Roughness of the thicker MoN layer $(\sim 2 \mathrm{~nm})$ prevented accurate determination of the $\mathrm{Mo}_{2} \mathrm{~N}$ layer thickness by $\mathrm{x}$-ray reflectivity. However, the width of the (111) peak established a lower limit of $\sim 4 \mathrm{~nm}$ on the $\mathrm{Mo}_{2} \mathrm{~N}$ thickness. The FWHM of the $\gamma-\mathrm{Mo}_{2} \mathrm{~N}(111)$ $\mathrm{x}$-ray rocking curve was $1.6 \pm 0.3^{\circ}, 22$ indicating that the Mo-rich layer is highly-ordered, although the IP orientation of this thin layer was not investigated due to practical limitations of the x-ray source. The same epitaxial relationship was obtained when $\mathrm{MoN}$ was deposited on $c-\mathrm{Al}_{2} \mathrm{O}_{3}$ with an ALD-grown $6 \mathrm{~nm}$ thick epitaxial (0001)AlN buffer layer.

ALD of $\mathrm{NbN}$ and TiN on $c-\mathrm{Al}_{2} \mathrm{O}_{3}$ resulted in cubic (111)-oriented films with two twin IP variants in agreement with previous studies of sputtered $\mathrm{NbN}^{213}$ and PLD-grown TiN films. ${ }^{5}$ The XRD results obtained for a $20 \mathrm{~nm}$ thick TiN film are shown in Figs. 1(c) and 11(d). The six $\operatorname{TiN}\{200\}$ peaks observed in Fig. 1)(d) indicate the presence of two twin domains related by a $180^{\circ}$ rotation about the [111] axis. This leads to a doubling of the expected threefold rotational symmetry about the [111] axis and mirrors the symmetry of the $\mathrm{Al}_{2} \mathrm{O}_{3}$ basal plane. The IP epitaxial relationship can therefore be described as $\pm[1 \overline{1} 0] \mathrm{TiN} \|[10 \overline{1} 0] \mathrm{Al}_{2} \mathrm{O}_{3}$. The FWHM of the TiN(111) x-ray rocking curve $e^{22}$ was $0.0169 \pm 0.0005^{\circ}$ which indicates a significantly higher degree of OP alignment compared to the $\mathrm{MoN} / c-\mathrm{Al}_{2} \mathrm{O}_{3}$ sample. The reduced OP mosaicity of the TiN film may be related to the lack of (a)

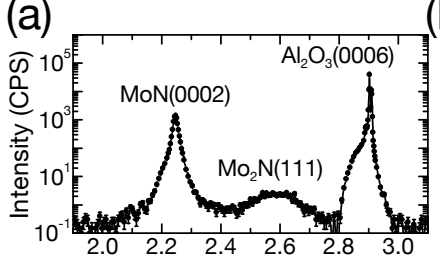

(b)

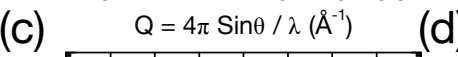

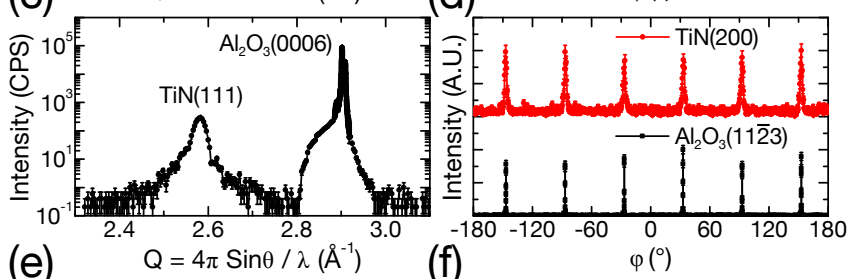

(e) $\quad \mathrm{Q}=4 \pi \operatorname{Sin} \theta / \lambda\left(\AA^{-1}\right) \quad(\mathrm{f})$

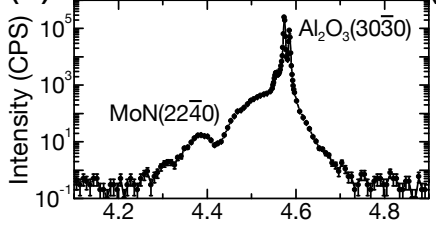

(g) $Q=4 \pi \sin \theta / \lambda\left(\AA^{-1}\right) \quad(h)$
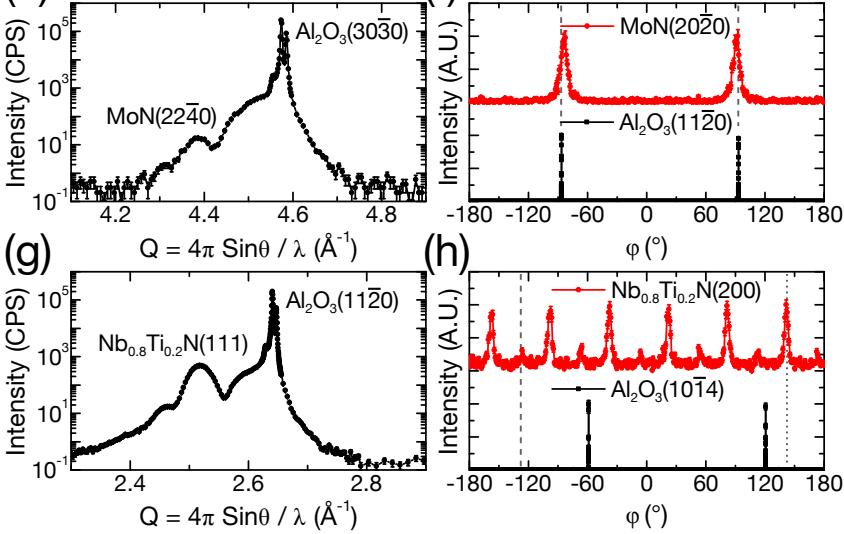

(h) $\quad \varphi\left(^{\circ}\right)$

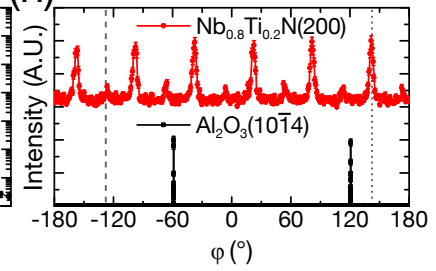

FIG. 1. (Color online) Scattered x-ray intensity from [(a), (c), (e), and (g)] longitudinal scans along the specular crystal truncation rod and [(b), (d), (f), and (h)] azimuthal scans through a set of off-specular reflections demonstrate the OP and IP epitaxy, respectively, for [(a) and (b)] $80 \mathrm{~nm} \mathrm{MoN} \mathrm{on}$ $c-\mathrm{Al}_{2} \mathrm{O}_{3},\left[(\mathrm{c})\right.$ and (d)] $20 \mathrm{~nm}$ TiN on $c-\mathrm{Al}_{2} \mathrm{O}_{3}$, [(e) and (f)] 50 $\mathrm{nm}$ MoN on $m-\mathrm{Al}_{2} \mathrm{O}_{3}$, and $[(\mathrm{g})$ and $(\mathrm{h})] 15 \mathrm{~nm} \mathrm{Nb_{0.8 }} \mathrm{Ti}_{0.2} \mathrm{~N}$ on $a-\mathrm{Al}_{2} \mathrm{O}_{3}$. The dashed lines in (f) are a guide for the eye. The dashed and dotted lines in (h) represent the $\phi$ positions of the [1100] and [0001] directions, respectively, of the $\mathrm{Al}_{2} \mathrm{O}_{3}$ substrate.

a secondary phase at the film-substrate interface. However, analysis of the $\{200\} \phi$ scan [Fig. 1(d)] indicates a broader IP texture $2.83 \pm 0.08^{\circ}$ (FWHM) compared to that of the $\mathrm{MoN} / c-\mathrm{Al}_{2} \mathrm{O}_{3}$ sample which is likely a consequence of the twinned TiN microstructure. Identical measurements of a $35 \mathrm{~nm}$ thick film of the isostructural $\mathrm{NbN}$ found an analogous result ${ }^{22}$ The OP mosaic and IP texture of the $\mathrm{NbN}$ film were $0.034 \pm 0.001^{\circ}$ and $1.98 \pm 0.03^{\circ}$, respectively.

The XRD results obtained for a $50 \mathrm{~nm}$ thick MoN film grown on $m-\mathrm{Al}_{2} \mathrm{O}_{3}$ are presented in Figs. 1(e) and 1 (f). The film is untwinned $\delta$-MoN with a single orientation described by $(11 \overline{2} 0)[1 \overline{1} 00] \mathrm{MoN} \|(10 \overline{1} 0)[1 \overline{2} 10] \mathrm{Al}_{2} \mathrm{O}_{3}$ and no evidence of a cubic phase. The relative orientations of $\mathrm{MoN}$ and $\mathrm{Al}_{2} \mathrm{O}_{3}$ are approximately equivalent to the $c$ $\mathrm{Al}_{2} \mathrm{O}_{3}$ case, with the hexagonal basal planes of film and substrate roughly parallel and the unit cell basis vectors offset by $30^{\circ}$ about the principal $c$-axis. However, 
Fig 1(f) reveals that the MoN peak centers are shifted along the azimuthal axis $\sim 2.5^{\circ}$ in opposite directions relative to each corresponding $\mathrm{Al}_{2} \mathrm{O}_{3}$ reflection. This is consistent with a tilting of the $\mathrm{MoN}(11 \overline{2} 0)$ plane away from the $\mathrm{Al}_{2} \mathrm{O}_{3}(10 \overline{1} 0)$ by $\sim 5^{\circ}$ about the $\mathrm{MoN}[\overline{1} 100]$ axis. A rocking curve measurement ${ }^{222}$ of the $\operatorname{MoN}(22 \overline{4} 0)$ reflection yielded a FWHM of $1.60 \pm 0.07^{\circ}$ indicating an OP mosaic comparable to the $\mathrm{MoN} / c-\mathrm{Al}_{2} \mathrm{O}_{3}$ sample. However, the azimuthal widths of the $(20 \overline{2} 0)$ and $(02 \overline{2} 0) \mathrm{MoN}$ peaks were $8.0 \pm 0.6^{\circ}$, indicating a considerably wider variation in IP texture. While numerous factors can influence film microstructure, such as differing modes of interfacial strain relaxation, the broadened IP alignment is not surprising given the lower symmetry of the $\mathrm{MoN}(11 \overline{2} 0)$ and $\mathrm{Al}_{2} \mathrm{O}_{3}(10 \overline{1} 0)$ planes compared to the high-symmetry (0001) planes.

On $a-\mathrm{Al}_{2} \mathrm{O}_{3}, \mathrm{ALD}$ of a $15 \mathrm{~nm}$ thick film of $\mathrm{Nb}_{0.8} \mathrm{Ti}_{0.2} \mathrm{~N}$ resulted in a cubic (111)-oriented film with two sets of twinned IP domains similar to the case of $\mathrm{NbN} / a-\mathrm{Al}_{2} \mathrm{O}_{3}$ reported in Ref.3. Fig.1 (1) demonstrates OP orientation of the film, with only $\mathrm{Nb}_{0.8} \mathrm{Ti}_{0.2} \mathrm{~N}(111)$ and $\mathrm{Al}_{2} \mathrm{O}_{3}(11 \overline{2} 0)$ reflections observed in a specular XRD scan. In contrast, the azimuthal scans shown in 1 $(\mathrm{h})$ revealed the presence of twelve equally-spaced $\mathrm{Nb}_{0.8} \mathrm{Ti}_{0.2} \mathrm{~N}\{200\}$ peaks rather than the three expected from a single crystallographic domain. The twelve observed $\{200\}$ peaks comprise two distinct sets which are offset by $30^{\circ}$ (modulo 60) and differ in integrated intensity by a factor of $\sim 6$. This indicates that the film contains primary and secondary pairs of $180^{\circ}$ twin IP domains which are offset by $90^{\circ}$ about the [111] axis. The IP orientations of the primary and secondary sets of twins were determined by comparison with a $\phi$ scan through the $\mathrm{Al}_{2} \mathrm{O}_{3}(10 \overline{1} 4)$ and $(01 \overline{1} \overline{4})$ reflections [Fig. 1(h)]. The orthogonal IP substrate directions [1100] and [0001] are oriented $\Delta \phi=-68.454^{\circ}$ and $\Delta \phi=21.546^{\circ}$, respectively, from the projection of the (1014) in the $\mathrm{Al}_{2} \mathrm{O}_{3}(11 \overline{2} 0)$ plane. Since the $\langle 1 \overline{1} 0\rangle$ directions are offset $30^{\circ}$ from the projection of the $\langle 200\rangle$ in the (111) plane, the IP orientations of the primary and secondary twins are therefore described by $\pm[1 \overline{1} 0] \mathrm{Nb}_{0.8} \mathrm{Ti}_{0.2} \mathrm{~N} \|[1 \overline{1} 00] \mathrm{Al}_{2} \mathrm{O}_{3}$ and $\pm[1 \overline{1} 0] \mathrm{Nb}_{0.8} \mathrm{Ti}_{0.2} \mathrm{~N} \|[0001] \mathrm{Al}_{2} \mathrm{O}_{3}$, respectively. The OP mosaic and IP texture of the $\mathrm{Nb}_{0.8} \mathrm{Ti}_{0.2} \mathrm{~N}$ film were $0.0186 \pm 0.0005^{\circ}$ and $4.6 \pm 0.2^{\circ}$.

On $r-\mathrm{Al}_{2} \mathrm{O}_{3}$, the growth directions of both hexagonal MoN and cubic TiN are such that no allowed reflections are positioned along the specular $\mathrm{Al}_{2} \mathrm{O}_{3}(1 \overline{1} 02)$ rod. Consequently, x-ray pole figures of the $\operatorname{MoN}\{20 \overline{2} 2\}$ and $\operatorname{TiN}\{200\}$ reflections were measured [Figs. 2(a) and 2(b), respectively] to determine film orientation in each case. Twelve MoN $\{20 \overline{2} 2\}$ peaks were observed for an $80 \mathrm{~nm}$ thick $\mathrm{MoN} / r-\mathrm{Al}_{2} \mathrm{O}_{3}$ film, as shown in Fig. 2(a). Analysis of the data found that the film is [12 12$]$-oriented, with two IP twin variants related by a $180^{\circ}$ rotation about the OP MoN $[1 \overline{2} 12]$ axis. For clarity, reflections from the two twins are labeled $\mathrm{MoN}^{a}$ and $\mathrm{MoN}^{b}$ in Fig. 2(a). Comparison with a $\phi$ scan through the $\mathrm{Al}_{2} \mathrm{O}_{3}(2 \overline{1} \overline{13})$ and (12.13) reflections (not shown) was used to determine the IP
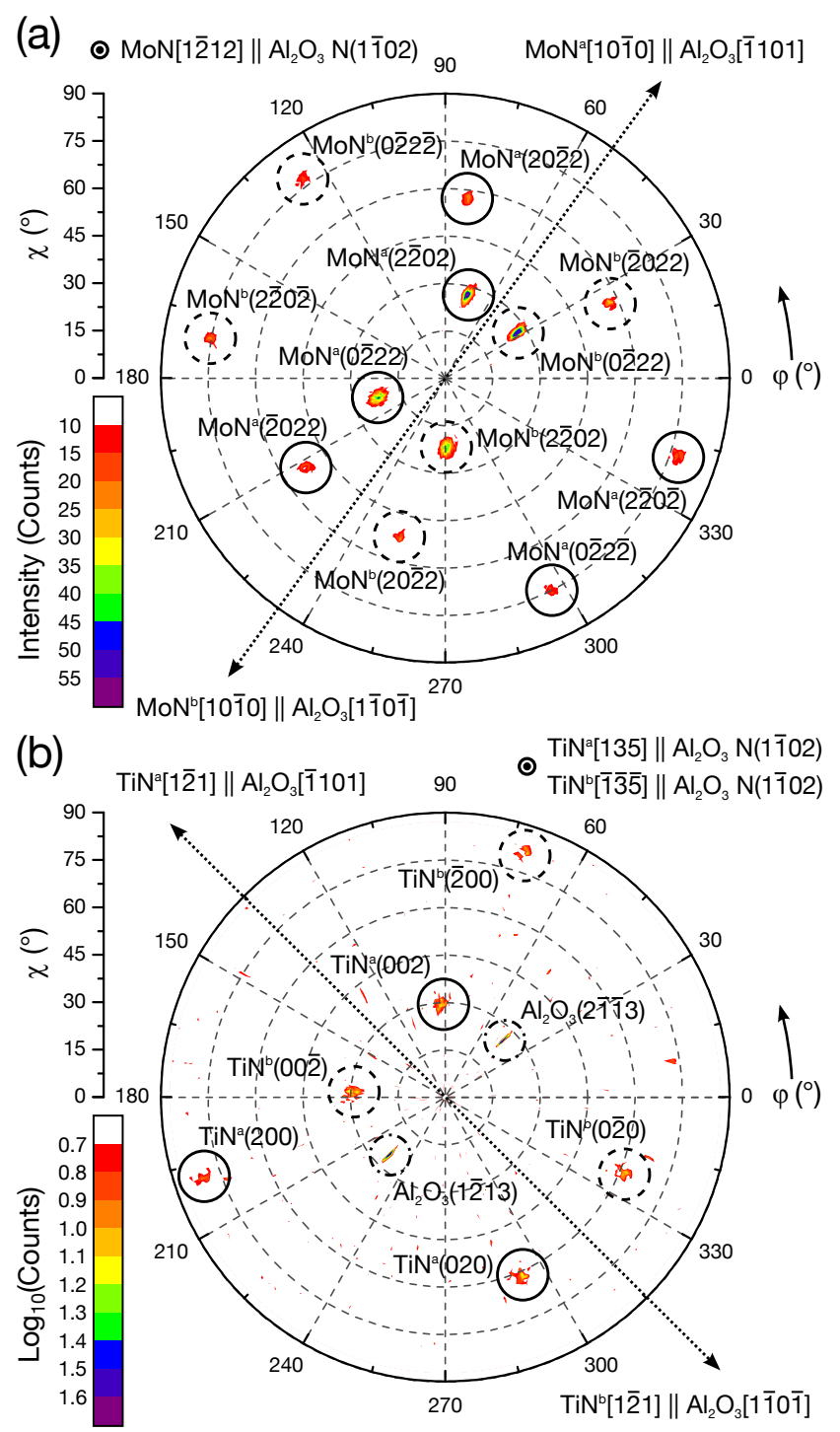

FIG. 2. (Color online) Pole figures of the (a) hexagonal $\{20 \overline{2} 2\}$ Bragg reflections for an $80 \mathrm{~nm} \mathrm{MoN} \mathrm{film} \mathrm{and} \mathrm{(b)} \mathrm{the} \mathrm{cubic}$ $\{200\}$ Bragg reflections for a $20 \mathrm{~nm}$ TiN film deposited on $r$ plane sapphire. Peaks from each twin variant are labeled with superscripts $a$ and $b$ and marked with solid and dashed circles. In the TiN measurement, peaks from the $\mathrm{Al}_{2} \mathrm{O}_{3}$ substrate are marked with dash-dot circles.

epitaxial orientation of the film, which is described by $\pm[10 \overline{1} 0] \mathrm{MoN} \|[\overline{1} 101] \mathrm{Al}_{2} \mathrm{O}_{3}$. Small displacements of the MoN peaks from their symmetric postions indicate that the $[1 \overline{2} 12]$ directions of the film domains are tilted from $\mathrm{Al}_{2} \mathrm{O}_{3}(1102)$ by $\sim 3^{\circ}$.

The $\operatorname{TiN}\{200\}$ x-ray pole figure obtained for a $20 \mathrm{~nm}$ $\mathrm{TiN} / r-\mathrm{Al}_{2} \mathrm{O}_{3}$ sample is shown in Fig. 2(b). Six film peaks were observed indicating the presence of two twin variants $\pm(135)[1 \overline{2} 1] \mathrm{TiN} \|(1 \overline{1} 02)[\overline{1} 101] \mathrm{Al}_{2} \mathrm{O}_{3}$ related by a $180^{\circ}$ rotation about the IP TiN[13.45] axis (or, equivalently, $180^{\circ}$ rotations about both the OP [135] and IP [1리] axes). In Fig. 2(b), peaks from the (135)- and $(\overline{1} \overline{3} \overline{5})$-oriented domains are labeled $\mathrm{TiN}^{a}$ and $\mathrm{TiN}^{b}$, re- 

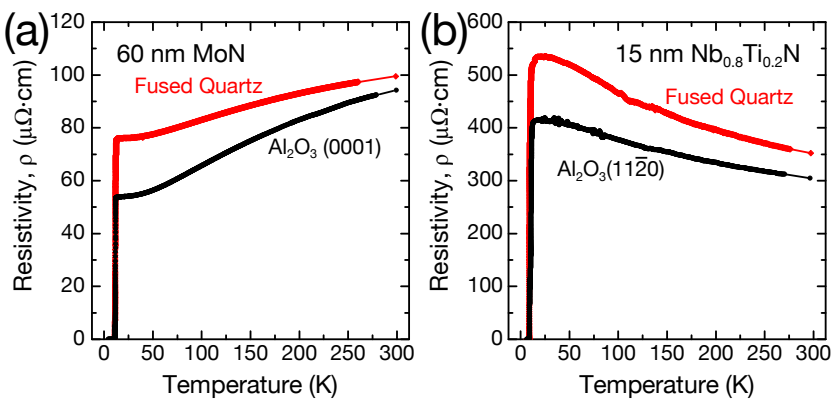

FIG. 3. (Color online) Electrical resistivity versus temperature measured for (a) a $60 \mathrm{~nm}$ MoN film deposited concurrently on (red diamonds) fused quartz and (black circles)

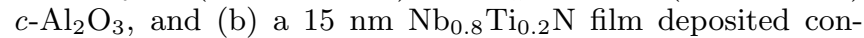
currently on (red diamonds) fused quartz and (black circles) $a-\mathrm{Al}_{2} \mathrm{O}_{3}$.

spectively. The observed structure was equivalent to that reported for sputtered $\mathrm{NbN}$ on $r-\mathrm{Al}_{2} \mathrm{O}_{3} \cdot 2 \mid 4$ The (21 $\overline{1} 3$ ) and $(1 \overline{2} 13)$ peaks from the $\mathrm{Al}_{2} \mathrm{O}_{3}$ substrate were visible in the $\operatorname{TiN}\{200\}$ pole figure due to the small difference in d-spacing between the TiN and $\mathrm{Al}_{2} \mathrm{O}_{3}$ reflections (2.1209 $\AA$ and $2.0853 \AA$, respectively), and conveniently illustrate the orientational registry of the film and substrate.

A comparison of electrical transport measurements of epitaxial and polycrystalline films found consistently more metallic behavior above the superconducting $T_{\mathrm{c}}$ in films deposited on sapphire with relatively minor change in $T_{\text {c }}$. Figs. 3 (a) and 3(b) show the film resistivity, $\rho(T)$, measured for two different cases, respectively: a relatively thick $60 \mathrm{~nm}$ MoN film deposited on fused quartz and $c-\mathrm{Al}_{2} \mathrm{O}_{3}$ and a thin $15 \mathrm{~nm} \mathrm{Nb} \mathrm{Nb}_{0.8} \mathrm{Ti}_{0.2} \mathrm{~N}$ film deposited on quartz and $a-\mathrm{Al}_{2} \mathrm{O}_{3}$. In both cases, the critical temperature, $T_{\mathrm{c} 0}$, of the film on sapphire was $<2 \%$ higher than the film on fused quartz. However, for $60 \mathrm{~nm} \mathrm{MoN,}$ the room temperature resistivity, $\rho_{300 \mathrm{~K}}$ is $\sim 5 \%$ lower and the residual resistance ratio $(\mathrm{RRR})\left(\rho_{300 \mathrm{~K}} / \rho_{20 \mathrm{~K}}\right)$ is $\sim 30 \%$ higher for the film grown on sapphire compared to the film on fused quartz. Likewise, for $15 \mathrm{~nm}$ $\mathrm{Nb}_{0.8} \mathrm{Ti}_{0.2} \mathrm{~N}, \rho_{300 \mathrm{~K}}$ and $\mathrm{RRR}$ for the sapphire sample were $\sim 15 \%$ lower and $\sim 10 \%$ higher, respectively, compared to the quartz sample. A similar effect was observed in Ref. 4 where a comparison of ultrathin twinned and untwinned $\mathrm{NbN}$ films found that while the presence of twinning resulted in $15 \% \rho_{300 \mathrm{~K}}$ and a $20 \%$ lower $\mathrm{RRR}$ $\left(\rho_{300 \mathrm{~K}} / \rho_{20 \mathrm{~K}}\right)$, the $T_{\mathrm{c}}$ was reduced by $<2 \%$.

In summary, high quality epitaxial films of $\mathrm{MoN}, \mathrm{NbN}$, TiN, and $\mathrm{Nb}_{x} \mathrm{Ti}_{1-x} \mathrm{~N}$ were prepared on sapphire substrates by ALD at a low growth temperature of $450{ }^{\circ} \mathrm{C}$. Observed orientations of MoN, NbN, and TiN deposited on $c-\mathrm{Al}_{2} \mathrm{O}_{3}$, and $\mathrm{Nb}_{x} \mathrm{Ti}_{1-x} \mathrm{~N}$ on $a-\mathrm{Al}_{2} \mathrm{O}_{3}$ were consistent with prior literature. Untwinned $(11 \overline{2} 0) \mathrm{MoN}$ was grown on $m$ - $\mathrm{Al}_{2} \mathrm{O}_{3}$, while on $r-\mathrm{Al}_{2} \mathrm{O}_{3}$ both (135)TiN and $[1 \overline{2} 12] \mathrm{MoN}$ grow with two IP twin domains. Epitaxial films were found to be more metallic than polycrystalline samples deposited concurrently on fused quartz. These results demonstrate the utility of ALD for the synthesis of epitaxial films of transition metal nitrides. This has significant implications for applications of nitride thin films where high crystalline quality is required in combination with moderate growth temperature, large-scale uniformity, precise thickness control, or conformal coating over complex-shaped surfaces.

This work was supported by the U.S. Department of Energy, Office of Science under contract No. DE-AC0206CH11357. We thank J. D. Emery for his critical reading of our manuscript.

${ }^{1}$ L. E. Toth, Transition Metal Carbides and Nitrides (Academic Press, New York, 1971).

${ }^{2}$ V. L. Noskov, Yu. V. Titenko, F. I. Korzhinskii, R. L. Zelenkevich, and V. A. Komashko, Sov. Phys. Crystallogr. 25, 504 (1980).

${ }^{3}$ S. J. Lloyd, D. M. Tricker, Z. H. Barber, and M. G. Blamire, Philos. Mag. A 81, 2317 (2001).

${ }^{4}$ R. Espiau de Lamaëstre, Ph. Odier, and J.-C. Villégier, Appl. Phys. Lett. 91, 232501 (2007).

${ }^{5}$ V. Talyansky, R. Vispute, R. Ramesh, R. Sharma, T. Venkatesan, Y. Li, L. Salamanca-Riba, M. Wood, R. Lareau, K. Jones, and A. Iliadis, Thin Solid Films 323, 37 (1998)

${ }^{6}$ Z. Wang, A. Kawakami, Y. Uzawa, and B. Komiyama, J. Appl. Phys. 79, 7837 (1996)

'Y. Zhang, N. Haberkorn, F. Ronning, H. Wang, N. A. Mara, M. Zhuo, L. Chen, J. H. Lee, K. J. Blackmore, E. Bauer, A. K. Burrell, T. M. McCleskey, M. E. Hawley, R. K. Schulze, L. Civale, T. Tajima, and Q. Jia, J. Am. Chem. Soc. 133, 20735 (2011) H. Luo, G. Zou, H. Wang, J. H. Lee, Y. Lin, H. Peng, Q. Lin, S. Deng, E. Bauer, T. M. McCleskey, A. K. Burrell, and Q. Jia, J. Phys. Chem. C 115, 17880 (2011)

${ }^{8}$ G. Zou, M. Jain, H. Zhou, H. Luo, S. A. Baily, L. Civale, E. Bauer, T. M. McCleskey, A. K. Burrell, and Q. Jia, Chem. Commun. , 6022 (2008)

${ }^{9}$ M. Ritala and M. Leskelä, in Handbook of Thin Film Materials, Vol. 1, edited by H. S. Nalwa (Academic Press, San Diego, CA, 2001) pp. 103-159.

${ }^{10}$ R. L. Puurunen, J. Appl. Phys. 97, 121301 (2005)

${ }^{11}$ V. Miikkulainen, M. Leskelä, M. Ritala, and R. L. Puurunen, J. Appl. Phys. 113, 021301 (2013)

${ }^{12}$ M. Asif Khan, J. N. Kuznia, R. A. Skogman, D. T. Olson, M. Mac Millan, and W. J. Choyke, Appl. Phys. Lett. 61, 2539 (1992)

${ }^{13}$ M. Asif Khan, R. A. Skogman, J. M. Van Hove, D. T. Olson, and J. N. Kuznia, Appl. Phys. Lett. 60, 1366 (1992) M. A. Khan, J. N. Kuznia, D. T. Olson, J. M. Van Hove, M. Blasingame, and L. F. Reitz, Appl. Phys. Lett. 60, 2917 (1992) M. Asif Khan, J. N. Kuznia, D. T. Olson, T. George, and W. T. Pike, Appl. Phys. Lett. 63, 3470 (1993) N. H. Karam, T. Parodos, P. Colter, D. McNulty, W. Rowland, J. Schetzina, N. El-Masry, and S. M. Bedair, Appl. Phys. Lett. 67, 94 (1995)

${ }^{14}$ N. Nepal, N. A. Mahadik, L. O. Nyakiti, S. B. Qadri, M. J. Mehl, J. K. Hite, and C. R. Eddy, Cryst. Growth Des. 13, 1485 (2013)

${ }^{15}$ S. Bedair, F. McIntosh, J. Roberts, E. Piner, K. Boutros, and N. El-Masry, J. Cryst. Growth 178, 32 (1997)

${ }^{16}$ H. Tsuchiya, M. Akamatsu, M. Ishida, and F. Hasegawa, Jpn. J. Appl. Phys. 35, L748 (1996)

${ }^{17}$ H. Kim, J. Vac. Sci. Technol. B 21, 2231 (2003)

${ }^{18}$ Th. Proslier, J. A. Klug, J. W. Elam, H. Claus, N. G. Becker, and M. J. Pellin, J. Phys. Chem. C 115, 9477 (2011) J. A. Klug, Th. Proslier, J. W. Elam, R. E. Cook, J. M. Hiller, H. Claus, N. G. Becker, and M. J. Pellin, J. Phys. Chem. C 115, 25063 (2011) Th. Proslier, J. Klug, N. C. Becker, J. W. Elam, and M. Pellin, ECS Trans. 41, 237 (2011) E. F. C. Driessen, P. C. J. J. Coumou, R. R. Tromp, P. J. de Visser, and T. M. Klapwijk, Phys. Rev. Lett. 109, 107003 (2012) P. Coumou, M. Zuiddam, E. Driessen, P. de Visser, J. Baselmans, and T. Klapwijk, IEEE T. Appl. Supercon. 23, 7500404 (2013) 
${ }^{19}$ J. W. Elam, M. D. Groner, and S. M. George, Rev. Sci. Instr. 73, $2981(2002)$

${ }^{20}$ M. Ritala, T. Asikainen, M. Leskelä, J. Jokinen, R. Lappalainen, M. Utriainen, L. Niinistö, and E. Ristolainen, Appl. Surf. Sci.
120, 199 (1997)

${ }^{21}$ H. M. Otte and A. G. Crocker, Phys. Stat. Sol. 9, 441 (1965).

${ }^{22}$ See supplimentary material at [url will be inserted by AIP] for additional XRD data. 